\title{
Aprotinin improves cerebral protection: Evidence from a survival porcine model
}

\author{
Vesa Anttila, MD, a,d Ikuo Hagino, MD, ${ }^{a}$ Yusuke Iwata, MD, ${ }^{e}$ Bret A. Mettler, MD, ${ }^{a}$ Hart G. W. Lidov, MD, ${ }^{c}$ \\ David Zurakowski, PhD, ${ }^{b}$ and Richard A. Jonas, $\mathrm{MD}^{\mathrm{e}}$
}

From the Departments of Cardiovascular Surgery, ${ }^{\mathrm{a}}$ Biostatistics, ${ }^{\mathrm{b}}$ and Pathology, ${ }^{\mathrm{c}}$ Children's Hospital Boston, Harvard Medical School, Boston, Mass; the Department of Surgery, ${ }^{\mathrm{d}}$ University Hospital of Oulu, Oulu, Finland; and the Department of Cardiovascular Surgery, ${ }^{e}$ Children's National Medical Center, Washington, DC.

Supported by a grant from the National Institutes of Health (2R01HL60922). Dr Anttila was supported by The Academy of Finland and The Finnish Medical Foundation.

Received for publication Aug 16, 2005; revisions received Jan 26, 2006; accepted for publication June 13, 2006.

Address for reprints: Richard A. Jonas, MD, Department of Cardiovascular Surgery, Children's National Medical Center, 111 Michigan Ave, Washington, DC 20010 (E-mail: rjonas@cnmc.org).

J Thorac Cardiovasc Surg 2006;132:948-53 $0022-5223 / \$ 32.00$

Copyright (๑) 2006 by The American Association for Thoracic Surgery

doi:10.1016/j.jtcvs.2006.06.017
Objective: Aprotinin is a serine protease inhibitor used during cardiac surgery to reduce blood loss and preserve platelet function. It has also been shown to reduce leukocyte activation during and after cardiopulmonary bypass. The goal of the study was to test the hypothesis that aprotinin could reduce cerebral injury after low-flow cardiopulmonary bypass and deep hypothermic circulatory arrest.

Methods: Sixteen piglets (mean weight, $13.6 \pm 1.3 \mathrm{~kg}$ ) were randomly assigned to receive aprotinin or placebo ( 8 animals per group) before a 120-minute period of deep hypothermic circulatory arrest $\left(15^{\circ} \mathrm{C}\right)$ or $25 \mathrm{~mL} \cdot \mathrm{kg}^{-1} \cdot \mathrm{min}^{-1}$ low-flow cardiopulmonary bypass $\left(25^{\circ} \mathrm{C}\right.$ or $\left.34^{\circ} \mathrm{C}\right)$. Piglets had a cranial window placed over the parietal cerebral cortex for direct examination of the microcirculation by means of intravital microscopy. Rhodamine-stained leukocytes were observed in postcapillary venules, with analysis for adhesion and rolling. Plasma was labeled with fluorescein isothiocyanate-dextran for assessment of functional capillary density. Neurologic and histologic scores were used as the primary outcome measures.

Results: During rewarming, the mean number of both rolling and adherent leukocytes was significantly lower after aprotinin administration $(P<.05)$. At 5 and 15 minutes of rewarming, functional capillary density recovered faster with aprotinin treatment $(P<.05)$. Functional outcome (neurologic deficit score) on postoperative day 1 was significantly improved in aprotinin-treated piglets $(P<.05)$.

Conclusions: Aprotinin reduces inflammation and improves neurologic outcome after a prolonged period of deep hypothermic circulatory arrest or low-flow cardiopulmonary bypass.

$\Lambda$ protinin is a broad-spectrum serine protease inhibitor that has been in clinical use since the late 1980s to reduce blood loss and preserve platelet function during cardiac surgery. ${ }^{1,2}$ Aprotinin has broad hemostatic properties that are mediated by blocking pathways of complement activation and fibrinolysis through inhibition of multiple proteases, including trypsin, plasmin, and kallikrein. ${ }^{3}$ Aprotinin has been shown to mitigate kallikrein-induced increases in serum bradykinin and associated brain edema in animal models. ${ }^{4}$ Within the circulation, aprotinin has been shown to significantly reduce neutrophil activation during and after cardiopulmonary bypass $(\mathrm{CPB}) .{ }^{5,6}$ Aprotinin directly reduces the inflammatory response at the leukocyte action level through inhibition of the upregulation of the proinflammatory CD11b integrin. ${ }^{5}$ This integrin plays a key role in the attachment of the neutrophil to the endothelial surface during an inflammatory response and also facilitates subsequent transmigration of the neutrophil into the extravascular space. Aprotinin has also been demonstrated to block leukocyte extravasation in a rat model by using intravital microcopy. ${ }^{7}$ This can be due to the targeting of soluble proteases, either directly, as in the case of elastase secreted by 

Abbreviations and Acronyms
ANOVA $=$ analysis of variance
$\mathrm{CPB}=$ cardiopulmonary bypass
DHCA = deep hypothermic circulatory arrest
FCD = functional capillary density
NDS = neurologic deficit score

the migrating cell, ${ }^{8}$ or indirectly, as in the case of matrix metalloproteinase activation by plasmin. ${ }^{9,10}$

Aprotinin has been shown to rescue dying neurons from cell death and to even restore their resting potential in the weaver mouse. ${ }^{11}$ The cell death in this mouse has been attributed to a mutation in the GIRK2 potassium channel, which renders the channel overly excitable. Because it has been shown that serine protease inhibitors have a 3-dimensional structure similar to that of potassiumchannel blockers, ${ }^{12}$ it could be hypothesized that the neuroprotection by aprotinin might be attributed to this blockage of the malfunctioning potassium channel. ${ }^{13}$

Protease inhibitors other than aprotinin have been demonstrated recently to reduce N-methyl-D-aspartate-mediated excitotoxic cerebral injury. We conducted this study to investigate whether aprotinin could improve cerebral outcome after a prolonged period of deep hypothermic circulatory arrest (DHCA) and low-flow CPB. Intravital microscopy was used to investigate cerebral microcirculation, including leukocyte activation and functional capillary density (FCD). Applying this technique in a survival experimental model provides the opportunity to study microvascular disturbances and compare them with functional and histologic outcomes.

\section{Materials and Methods}

\section{Animals}

Sixteen juvenile (6-7 weeks) Yorkshire piglets with a mean body weight $13.6 \pm 1.3 \mathrm{~kg}$ were randomly assigned to receive either aprotinin or saline (8 animals per group) before a 120-minute period of DHCA at $15^{\circ} \mathrm{C}$ or low-flow perfusion $\left(25 \mathrm{~mL} \cdot \mathrm{kg}^{-1}\right.$. $\min ^{-1}$ ) at $25^{\circ} \mathrm{C}$ or $34^{\circ} \mathrm{C}$.

All animals received humane care in accordance with the "Principles of Laboratory Animal Care" formulated by the National Society for Medical Research and the "Guide for the Care and use of Laboratory Animals" prepared by the Institute of Laboratory Animal Resources, National Research Council, and published by the National Academy Press, revised in 1996.

The study was approved by the Animal Care and Use Committee of the Children's Hospital Boston.

\section{Drug Administration}

Piglets in the aprotinin group received the drug (Trasylol; Bayer, West Haven, Conn) according to the following prescription: loading dose of aprotinin of 30,000 KIU/kg (kallikrein inhibitor units) administered intravenously, pump priming of 30,000 KIU/kg, and maintenance intravenous infusion of $10,000 \mathrm{KIU} \cdot \mathrm{kg}^{-1} \cdot \mathrm{h}^{-1}$. Aprotinin was discontinued within 2 hours after weaning from CPB. Control animals received the same volume of saline infusion. The aprotinin dose was the same as that used clinically. Randomization envelopes were opened, drug or saline syringes were prepared by a laboratory technician, and the codes were broken after the entire series of experiments was accomplished. Therefore all observers in every data recording point were unaware of whether the animal received aprotinin or was a control animal.

\section{Surgical Preparation}

After premedication with an intramuscular injection of ketamine $(20 \mathrm{mg} / \mathrm{kg}$ ) and xylazine $(4 \mathrm{mg} / \mathrm{kg})$, the piglets were intubated and ventilated with $21 \%$ oxygen at a respiratory rate of between 18 to 20 breaths/min to achieve an arterial $\mathrm{PCO}_{2}$ of 35 to $40 \mathrm{~mm} \mathrm{Hg}$. After induction with fentanyl $(25 \mu \mathrm{g} / \mathrm{kg}$ administered intravenously), anesthesia was maintained with continuous infusion of fentanyl $\left(25 \mu \mathrm{g} \cdot \mathrm{kg}^{-1} \cdot \mathrm{h}^{-1}\right)$, midazolam $\left(0.2 \mathrm{mg} \cdot \mathrm{kg}^{-1} \cdot \mathrm{h}^{-1}\right)$, and pancuronium $\left(0.2 \mathrm{mg} \cdot \mathrm{kg}^{-1} \cdot \mathrm{h}^{-1}\right)$. Temperature probes were placed into the esophagus and rectum. A cannula (19G Intracath; Becton Dickinson, Sandy, Utah) was inserted in the left superficial femoral artery and advanced into the abdominal aorta for continuous blood pressure monitoring. For anesthesia infusion, a cannula (19G Intracath, Becton Dickinson) was introduced through the right femoral vein into the inferior vena cava. After systemic heparinization (300 IU/kg administered intravenously) and a right anterolateral thoracotomy in the third intercostal space, an $8 \mathrm{~F}$ arterial cannula (Bio-Medicus; Medtronic Inc, Eden Prairie, Minn) was inserted through the right femoral artery into the abdominal aorta, and a 28F cannula (Harvey; Bard, Tewksbury, Mass) was inserted into the right atrium for CPB. The piglets were positioned prone in a stereotactic frame, and a cranial window $(15 \times 15 \mathrm{~mm})$ was created over the parietal cerebral cortex with an electric drill. After incision of the dura, the surface (pial) vessels were visualized. The cranial window was closed with a glass cover slip.

\section{Experimental Protocol}

Sixteen piglets were randomized according to the experimental protocol. Six piglets were subjected to the $15^{\circ} \mathrm{C}$ DHCA, 6 piglets (3 per group) to the $25^{\circ} \mathrm{C}$ low-flow $\mathrm{CPB}$ with a flow rate of $25 \mathrm{~mL}$. $\mathrm{kg}^{-1} \cdot \min ^{-1}$, and 4 piglets (2 per group) to the $34^{\circ} \mathrm{C}$ low-flow $\mathrm{CPB}$ with a flow rate of $25 \mathrm{~mL} \cdot \mathrm{kg}^{-1} \cdot \mathrm{min}^{-1}$. The duration of DHCA and the low-flow period was 120 minutes. In every group half of the animals were randomized to receive aprotinin or saline according to the protocol.

\section{CPB Technique}

The CPB circuit consisted of a roller pump (Cardiovascular Instrument Corp, Wakefield, Mass), membrane oxygenator (Minimax; Medtronic Inc, Anaheim, Calif), and sterile tubing with a $40-\mu \mathrm{m}$ arterial filter. Fresh whole blood from a donor pig was transfused into the prime to adjust the hematocrit level to $30 \%$. Methylprednisolone $(30 \mathrm{mg} / \mathrm{kg})$, furosemide $(0.25 \mathrm{mg} / \mathrm{kg})$, sodium bicarbonate $7.4 \%(10 \mathrm{~mL})$, and cephazolin sodium $(25 \mathrm{mg} / \mathrm{kg})$ were added to the prime before the start of CPB. The $\mathrm{pH}$-stat strategy was used (sweep gas $95 \% \mathrm{O}_{2} / 5 \% \mathrm{CO}_{2}$ ). The gas flow was adjusted to achieve an arterial $\mathrm{PCO}_{2}$ of 40 to $45 \mathrm{~mm} \mathrm{Hg}$ (corrected to nasopharyngeal temperature). After baseline recordings, $\mathrm{CPB}$ 
with a flow rate of $100 \mathrm{~mL} \cdot \mathrm{kg}^{-1} \cdot \mathrm{min}^{-1}$ was started, and the animals were perfused for 10 minutes at normothermia (esophageal temperature, $37^{\circ} \mathrm{C}$ ). Ventilation was stopped after the establishment of CPB. The piglets underwent 40 minutes of cooling on $\mathrm{CPB}$ to an esophageal temperature of $15^{\circ} \mathrm{C}, 25^{\circ} \mathrm{C}$, or $34^{\circ} \mathrm{C}$. After cooling, DHCA or low-flow perfusion at a flow rate of $25 \mathrm{~mL}$. $\mathrm{kg}^{-1} \cdot \min ^{-1}$ was initiated for 120 minutes. Before rewarming, sodium bicarbonate $7.4 \%(10 \mathrm{~mL})$, methylprednisolone $(30 \mathrm{mg} /$ $\mathrm{kg})$, furosemide $(0.25 \mathrm{mg} / \mathrm{kg})$, and mannitol $(0.5 \mathrm{~g} / \mathrm{kg})$ were administered into the pump. During 40 minutes of rewarming, animals were warmed to $37^{\circ} \mathrm{C}$ with a flow rate of $100 \mathrm{~mL} \cdot \mathrm{kg}^{-1}$. $\min ^{-1}$. The heart was defibrillated, if necessary, at an esophageal temperature of $30^{\circ} \mathrm{C}$. Ventilation $(100 \%$ oxygen) was started 10 minutes before weaning from CPB. Protamine $(5 \mathrm{mg} / \mathrm{kg})$ was administered intravenously after the animal was hemodynamically stable. The wounds were closed in a sterile fashion.

Arterial pressure was monitored continuously throughout each experiment and was recorded every 15 minutes. Hemoglobin value, hematocrit value, glucose value, lactate value, $\mathrm{PO}_{2}, \mathrm{PCO}_{2}$, and $\mathrm{pH}$ were measured every 15 minutes on $\mathrm{CPB}$, at 30 minutes after $\mathrm{CPB}$, and once an hour until extubation with a blood gas analyzer (Stat Profile 9; Nova, Waltham, Mass).

Animals remained sedated and paralyzed with a continuous infusion of fentanyl $\left(50 \mu \mathrm{g} \cdot \mathrm{kg}^{-1} \cdot \mathrm{h}^{-1}\right)$, midazolam $(0.2 \mathrm{mg}$. $\left.\mathrm{kg}^{-1} \cdot \mathrm{h}^{-1}\right)$, and pancuronium $\left(0.2 \mathrm{mg} \cdot \mathrm{kg}^{-1} \cdot \mathrm{h}^{-1}\right)$ and were mechanically ventilated ( $21 \%$ oxygen) and monitored continuously for 12 hours after the operation. The chest tubes were removed, and the animals were extubated.

\section{Intravital Fluorescence Microscopy}

An epifluorescence microscope (Model MZ FLIII; Leica, Heerbrugg, Switzerland) with a 100-W mercury gas discharge lamp equipped with a rapid filter exchanger was placed over the cranial window. The microscope included 2 sets of filters: a blue filter set (450-490 nm excitation/>515-nm emission wavelength) for visualization of fluorescein fluorescence and a green filter set (536-556 $\mathrm{nm}$ excitation/>590-nm emission wavelength) for visualization of rhodamine-labeled leukocytes. The microscope images from the charge-coupled device video camera (Dage-300-RC; Dage-MTI, Michigan City, Ind) were time stamped with a time-code generator (VTG-33; For-A, Tokyo, Japan). The images were transferred to a high-resolution 12-inch monitor (Dage HR-1000, Dage-MTI) and videotaped. A Scion LG-3 frame grabber card (Scion Corp, Frederick, Md) and computer-assisted image analysis system (NIH Image; National Institutes of Health, Bethesda, Md) were used for subsequent offline analysis. The final magnification on the monitor was $400 \times$.

For the assessment of leukocyte-endothelial cell interactions, the circulating leukocytes were labeled with $2 \mathrm{~mL}$ of rhodamine-6G $0.2 \%$ (Sigma Chemical, St Louis, Mo). The numbers of adherent (adherent leukocytes/100- $\mu \mathrm{m}$ vessel length) and rolling (rollers/ $100-\mu \mathrm{m}$ vessel length per minute) leukocytes in 20 - to $30-\mu \mathrm{m}$ diameter postcapillary venules were observed. A green filter set was used to excite rhodamine fluorescence.

Plasma was labeled with $1 \mathrm{~mL}$ of fluorescein isothiocyanatedextran 5\% (150 kD, Sigma Chemical) before each subsequent measurement to visualize microvascular FCD, defined as the total length of erythrocyte-perfused capillaries per observation area, and the diameter of arteries and venules. The fluorescein isothiocyanate fluorescence was excited with the blue filter set. The plasma became highlighted, and the red blood cells appeared dark (negative contrast). The diameter of $60-$ to $100-\mu \mathrm{m}$ arterial and venous cerebrocortical microvessels was measured from video still images by using an image analysis program. On average, 4 to 5 arterioles and 3 to 4 venules per observation area were measured.

Intravital fluorescence microscopy was performed at baseline; at 10 minutes of normothermic CPB; at 20 minutes of cooling; at the end of cooling; at every 15 minutes during the low-flow period; at 5, 15, 30, and 40 minutes of rewarming; and at 30 and 60 minutes after weaning from CPB. The duration of brain tissue epi-illumination was limited to less than 1 minute to avoid thermal injury of tissue, and it was always shut off between video recordings.

\section{Postoperative Evaluation}

After the operation, neurologic and behavioral evaluations were performed at 24-hour intervals by a senior veterinarian blinded to the experimental protocol beginning on postoperative day 1 . Neurologic scoring was adapted from the neurologic deficit score (NDS: $500=$ brain death, $0=$ normal). ${ }^{14}$

\section{Histopathologic Analysis}

On postoperative day 4 , all surviving piglets were sedated by using intramuscular induction with ketamine $(20 \mathrm{mg} / \mathrm{kg})$ and xylazine $(4 \mathrm{mg} / \mathrm{kg})$ and anesthetized with intravenous fentanyl $(50 \mu \mathrm{g} / \mathrm{kg})$. After a midline sternotomy, heparin (300 IU/kg) was administered, and a cannula was inserted into the left common carotid artery. The aortic arch was clamped, and $1 \mathrm{~L}$ of Plasmalyte solution (Baxter, Deerfield, Ill) was infused through the left common carotid artery. Blood was suctioned from the superior vena cava until the perfusate was clear of blood. Then $3 \mathrm{~L}$ of $10 \%$ formalin solution was perfused through the brain in the same manner to accomplish perfusion fixation. The entire head of the piglet was immersed in $10 \%$ formalin for a week, and the brain was harvested and fixed with $10 \%$ formalin solution for the histologic assessment. ${ }^{15}$

The preparation of the cerebral specimens and the details of used analyses have been described previously. ${ }^{15,16}$ Specimens from 6 regions of the brain (neocortex, hippocampus, dentate gyrus, caudate nucleus, thalamus, and cerebellum) were examined. Histologic damage was scored by using the following criteria: 5, cavitated lesions with necrosis; 4, significant damage to neurons; 3, large clusters of injured neurons; 2 , small clusters of damaged neurons; 1 , isolated neuronal damage; 0 , normal. A single neuropathologist (H.G.W.L.) examined all specimens in a blinded fashion.

\section{Statistical Analysis}

Continuous variables are expressed as means \pm standard deviation. Kolmogorov-Smirnov test indicated that the variables followed a normal distribution. Repeated-measures analysis of variance (ANOVA) was used to evaluate changes over time and to compare rates of change between the aprotinin and control groups with respect to changes in FCD over time, as well as to evaluate any differences between the 2 groups regarding mean arterial pressure, hematocrit value, arterial $\mathrm{pH}$, and hemoglobin value. ${ }^{17}$ Two-way ANOVA was used to test for differences in leukocyte counts (adherent and rolling) during rewarming and neurologic 
recovery by evaluating F-tests' main effects for temperature and the use of aprotinin and the 2-way interaction. This multivariable approach allowed an interpretation of the effects of temperature and aprotinin treatment. Plots were constructed to show mean values of leukocytes and NDSs for animals in the no-aprotinin (control) group and the aprotinin (treatment) group for each DHCA or low-flow CPB condition. A significant downward slope indicated that aprotinin reduced the number of leukocytes during rewarming or led to lower neurologic/histologic scores. A difference in intercepts between the $15^{\circ} \mathrm{C}$ and DHCA, $25^{\circ} \mathrm{C}$ and $25 \mathrm{~mL}$. $\mathrm{kg}^{-1} \cdot \min ^{-1}$, and $34^{\circ} \mathrm{C}$ and $25 \mathrm{~mL} \cdot \mathrm{kg}^{-1} \cdot \mathrm{min}^{-1}$ groups indicated differences in outcomes (leukocyte counts or brain injury scores) as a result of temperature conditions. The nonparametric Spearman rho $(\rho)$ correlation coefficient was used to measure the association between intravital microscopy data and temperature and flow rate. Statistical analysis was performed with the SPSS package (version 13.0; SPSS Inc, Chicago, Ill).

\section{Results}

There were no statistically significant differences at baseline (before $\mathrm{CPB}$ ) between the experimental groups regarding hematocrit values, blood gases, mean arterial pressure, whole-body lactate values, or intravital microscopy data. Mean arterial pressure, hematocrit values, arterial $\mathrm{pH}$, and hemoglobin values were analyzed by using 2-way repeatedmeasures ANOVA. No significant differences were found between the aprotinin and control groups for any of these 4 variables throughout the time period from baseline, low-flow bypass, and rewarming to weaning from the pump. The F-test for the aprotinin group versus the control group was not significant for mean arterial pressure $(\mathrm{F}=0.22, P=.65)$, hematocrit values $(\mathrm{F}=0.71, P=.43), \mathrm{pH}(\mathrm{F}=1.94, P=.20)$, or hemoglobin values $(\mathrm{F}=0.53, P=.49)$. In the baseline hematocrit levels were $32 \% \pm 2 \%$ in the aprotinin group and $32 \% \pm 4 \%$ in the control group. Sixty and 180 minutes after weaning from pump, hematocrit levels were $28 \% \pm 4 \%$ and $27 \% \pm 2 \%$ and $26 \% \pm 3$ and $25 \% \pm 3 \%$, respectively.

\section{Leukocyte-Endothelial Cell Interactions}

At the end of the cooling period, more adherent leukocytes were found at $34^{\circ} \mathrm{C}$ compared with at $15^{\circ} \mathrm{C}(P=.04)$ in postcapillary venules. At that time point, temperature was positively correlated with the number of adherent leukocytes (Spearman $\rho=0.50, P<.05$ ).

A significant inverse correlation was found between the use of aprotinin and the number of rolling and adherent leukocytes during the rewarming period (Spearman $\rho=$ -0.49 to $-0.60, P<.05)$. Aprotinin was a multivariable predictor of a decreased number of rolling leukocytes during the rewarming period $(\mathrm{F}=5.25, P=.04)$. At $15^{\circ} \mathrm{C}$, the mean number of rolling leukocytes with aprotinin was $0.8 \pm$ 0.4 , and without aprotinin, it was $1.5 \pm 0.7$. At $25^{\circ} \mathrm{C}$, the corresponding numbers were $1.8 \pm 0.3$ and $4.3 \pm 2$, and at $34^{\circ} \mathrm{C}$, they were $2.2 \pm 1.7$ and $3.4 \pm 1.5$, respectively (Figure 1, A). Lower temperature and aprotinin were mul- tivariable predictors of the decreased number of adherent leukocytes during the rewarming period $(\mathrm{F}=7.53, P=$ .008 and $\mathrm{F}=13.56, P=.003$, respectively). The mean number of adherent leukocytes was $5.0 \pm 0.4$ with aprotinin and $5.8 \pm 2.1$ without aprotinin at $15^{\circ} \mathrm{C}$. At $25^{\circ} \mathrm{C}$, the corresponding numbers were $3.2 \pm 0.5$ and $4.6 \pm 0.3$, and at $34^{\circ} \mathrm{C}$, they were $5.9 \pm 0.5$ and $7.0 \pm 0.3$, respectively. There were no significant 2-way interactions between temperature and aprotinin (Figure 1,B).

\section{Functional Capillary Density}

FCD increased in all animals from baseline (100\%) to normothermic CPB $(115 \% \pm 5 \%)$, but there were no differences between the groups. At the end of cooling, FCD was significantly less in animals at $15^{\circ} \mathrm{C}(91 \% \pm 1 \%)$ compared with that seen in the $34^{\circ} \mathrm{C}$ group $(103 \% \pm 11 \%, P<.05)$.

At the beginning of rewarming ( 5 and 15 minutes), FCD recovered significantly faster after aprotinin administration relative to that seen in control animals $(78.4 \% \pm 14.4 \%$ vs $62.8 \% \pm 20.7 \%[\mathrm{~F}=14.43, P=.003]$ and $96.3 \% \pm 12.9 \%$ vs $83.4 \% \pm 21.7 \%[\mathrm{~F}=12.88, P=.03]$, respectively). At these time points, after 2 hours of DHCA at $15^{\circ} \mathrm{C}$, aprotinin treatment was associated with significantly improved FCD compared with that seen in control animals $(P<.05)$.

\section{Morbidity and Mortality}

All animals were stable during the surgical procedures and survived to at least the first postoperative day. Fourteen of the 16 animals survived the planned 4 days after the operation and were electively killed. One control animal subjected to $15^{\circ} \mathrm{C}$ DHCA stayed comatose and died on postoperative day 1 of severe brain damage, and another animal in the $15^{\circ} \mathrm{C}$ DHCA with aprotinin group was killed after repeated seizures on postoperative day 2 .

\section{Neurologic and Behavioral Evaluations}

The NDS category showed relatively rapid recovery in all surviving animals. DHCA was predictive of delayed neurologic recovery $(\mathrm{F}=20.48, P<.001)$, whereas aprotinin was predictive of faster recovery $(\mathrm{F}=4.71, P<.05$; Figure $1, C)$.

\section{Histologic Assessment}

Histologic scores were quite low, except when DHCA was used. When a $25 \mathrm{~mL} \cdot \mathrm{kg}^{-1} \cdot \mathrm{min}^{-1}$ flow rate was used, no significant differences in histologic scores were found between aprotinin-treated and control animals, although at $34^{\circ} \mathrm{C}$, scores tended to be lower with aprotinin $(\mathrm{F}=2.79$, $P=.12$; Table 1 and Figure $1, D)$.

\section{Discussion}

The results of this study indicate that aprotinin might improve cerebral outcome after a prolonged period of DHCA and low-flow CPB. A better outcome was seen in terms of inflammatory response, faster recovery of FCD, and NDSs. 

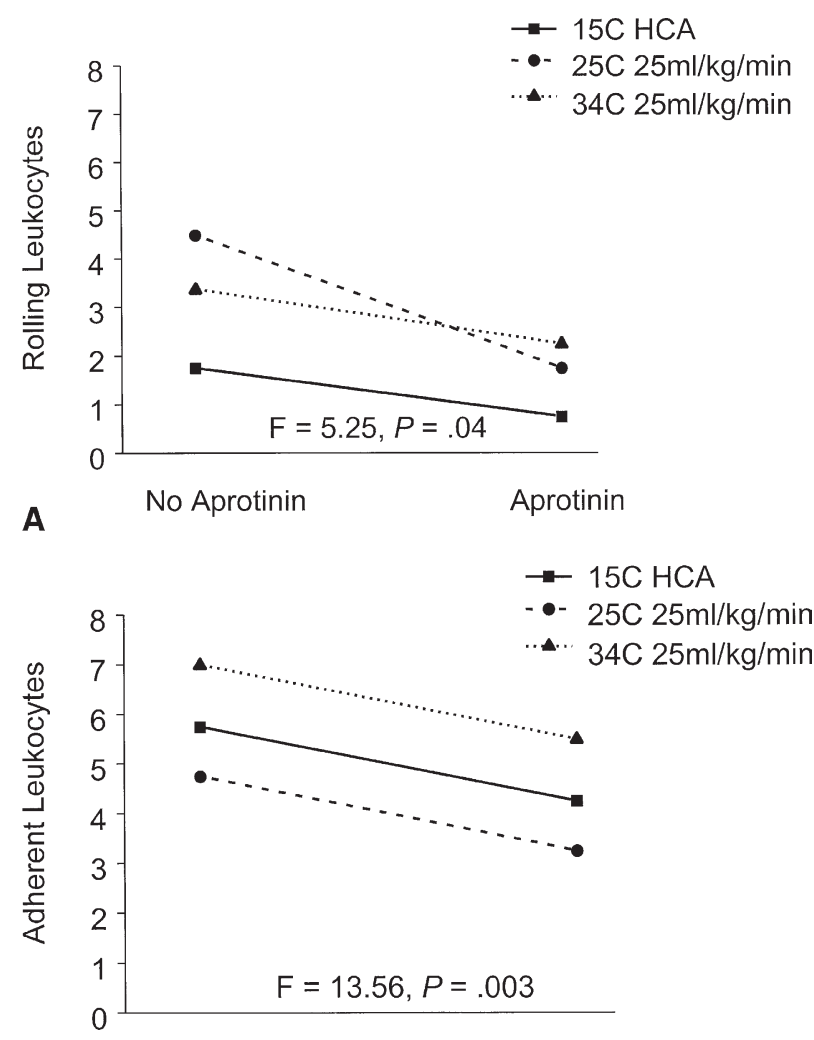

B

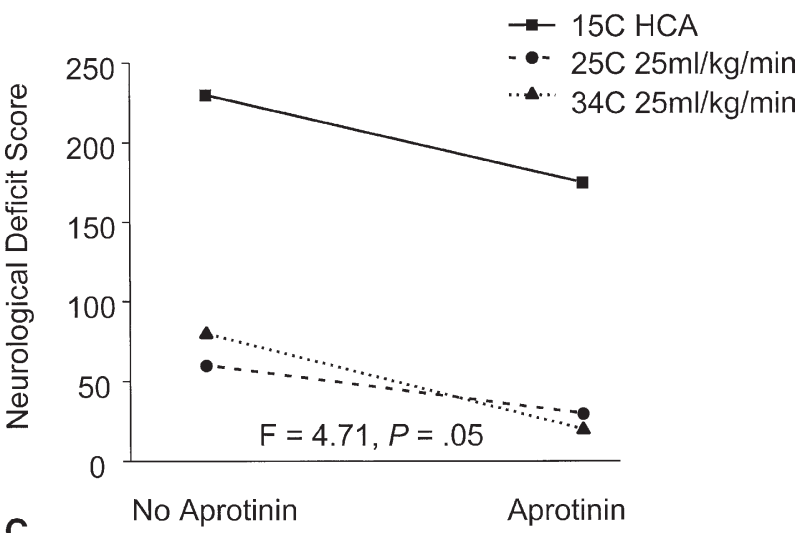

C

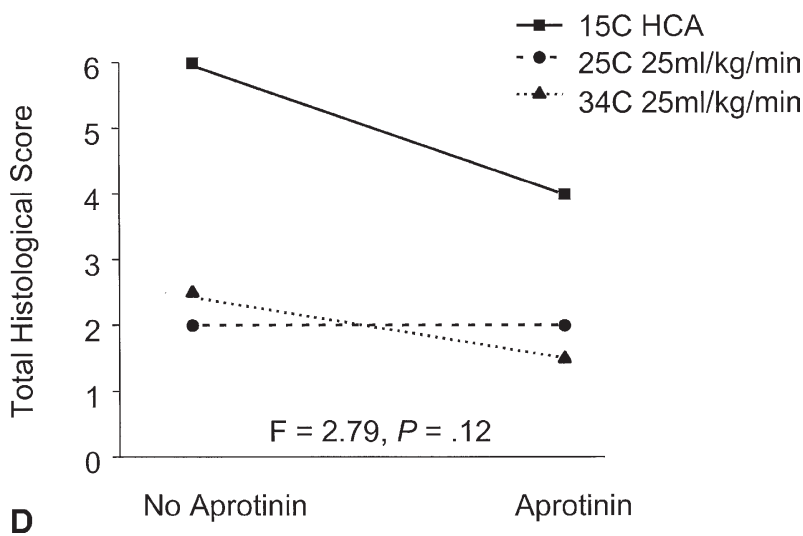

The results confirm those of previous studies suggesting that aprotinin has a neuroprotective effects. ${ }^{11}$

A principal finding of this study was that aprotinin mitigates leukocyte activation during CPB. White cell activation, adhesion to endothelium, and subsequent transendothelial migration have been shown to result from CPB as a part of the systemic inflammatory response. ${ }^{18}$ Adhesion molecules, including selectins, $\beta_{2}$-integrins, and the immunoglobulin superfamily, play important roles during inflammation. ${ }^{19}$ It has been shown that leukocyte expression of $\beta_{2}$-integrin increases significantly during $\mathrm{CPB}$, but aprotinin administration prevents this. ${ }^{6}$ Our previous study showed that higher temperature was correlated with a greater number of activated leukocytes during $\mathrm{CPB} .{ }^{20}$ In the current study we were able to demonstrate that aprotinin administration reduces the number of adherent leukocytes in postcapillary venules during the rewarming period after mildly hypothermic $\left(34^{\circ} \mathrm{C}\right)$ bypass.

An interesting finding of our study was that after aprotinin administration, FCD recovered more rapidly during the early rewarming period after a prolonged period of DHCA. This finding contrasts with previous concerns that aprotinin could result in clotting in small vessels when used in the setting of DHCA. Nevertheless, our finding is supported by a previous study demonstrating that aprotinin inhibits thrombin-induced platelet activation by preventing proteolysis of the protease-activated receptor 1 receptor, and that suggests instead that aprotinin might have significant antithrombotic effects. ${ }^{21}$ At 5 minutes of rewarming after 2 hours of DHCA, we detected areas of the cerebral microcirculation with very slow or no-flow and low capillary density, but there were fewer of these areas after aprotinin

Figure 1. A, Use of aprotinin was predictive of a decreased number of rolling leukocytes during rewarming $(F=5.25, P=$ .04), which was consistent for all 3 conditions. Data points represent actual mean values. No error bars are shown because of small sample sizes, although there is a description in the text. $B$, Use of aprotinin was predictive of a decreased number of adherent leukocytes during rewarming $(F=13.56, P=.003)$, which is consistent for all 3 hypothermic circulatory arrest and low-flow bypass conditions. Data points represent actual mean values. No error bars are shown because of small sample sizes, although there is a description in the text. C, Aprotinin was a multivariable predictor for faster neurologic recovery $(F=4.71$, $P<.05)$, which is consistent for all 3 hypothermic circulatory arrest and low-flow bypass conditions. Data points represent actual mean values. D, Histologic scores were low, except when DHCA was used. By using a flow rate of $25 \mathrm{~mL} \cdot \mathrm{kg}^{-1} \cdot \mathrm{min}^{-1}$, no significant differences in histologic scores were found between aprotinin-treated and control animals. However, at $34^{\circ} \mathrm{C}$, scores tended to be lower with aprotinin $(F=2.79, P=.12)$. HCA, Hypothermic circulatory arrest. 
TABLE 1. Regional histologic scores and neurologic deficit scores by temperature and flow rate during DHCA or low-flow bypass

\begin{tabular}{|c|c|c|c|c|c|c|c|c|c|}
\hline \multirow{2}{*}{$\begin{array}{l}\text { Temperature, flow } \\
\left(\mathrm{mL} \cdot \mathrm{kg}^{-1} \cdot \mathrm{min}^{-1}\right)\end{array}$} & \multirow[b]{2}{*}{$\mathbf{N}$} & \multicolumn{6}{|c|}{ Histologic scores } & \multirow{2}{*}{$\frac{\text { Sum }}{\text { Total score }}$} & \multirow[b]{2}{*}{ NDS POD 1} \\
\hline & & Neocortex & Hippocampus & Dentate gyrus & Caudate nucleus & Thalamus & Cerebellum & & \\
\hline $34^{\circ} \mathrm{C}, 25$, control & 2 & $0(0-0)$ & $0(0-0)$ & $0(0-0)$ & $0(0-0)$ & $0(0-0)$ & $3(0-3)$ & $3(2-3)$ & $80 \pm 14$ \\
\hline $34^{\circ} \mathrm{C}, 25$, aprotinin & 2 & $0(0-0)$ & $0(0-0)$ & $0(0-0)$ & $0(0-0)$ & $0(0-0)$ & $2(0-2)$ & $2(1-2)$ & $20 \pm 0$ \\
\hline $25^{\circ} \mathrm{C}, 25$, control & 3 & $0(0-0)$ & $0(0-0)$ & $0(0-0)$ & $0(0-0)$ & $0(0-0)$ & $2(0-3)$ & $2(2-3)$ & $60 \pm 30$ \\
\hline $25^{\circ} \mathrm{C}, 25$, aprotinin & 3 & $0(0-0)$ & $0(0-2)$ & $0(0-0)$ & $0(0-0)$ & $0(0-3)$ & $2(0-2)$ & $2(2-4)$ & $37 \pm 21$ \\
\hline $15^{\circ} \mathrm{C}, \mathrm{HCA}$, control & 3 & $2(0-3)$ & $0(0-0)$ & $0(0-0)$ & $2(0-3)$ & $0(0-0)$ & $3(0-3)$ & $6(5-9)$ & $157 \pm 84^{*}$ \\
\hline $15^{\circ} \mathrm{C}, \mathrm{HCA}$, aprotinin & 3 & $0(0-0)$ & $0(0-0)$ & $0(0-2)$ & $1(0-2)$ & $0(0-0)$ & $1(0-2)$ & $4(3-5)$ & $212 \pm 32^{*}$ \\
\hline
\end{tabular}

Histologic data are presented as medians with interquartile ranges, and neurologic deficit score data are presented as means \pm standard deviation. NDS POD1, Neurologic deficit score on postoperative day $1 ; H C A$, hypothermic circulatory arrest. $* P<.05$ compared with each of the other low-flow conditions.

administration. However, the low- and no-flow areas recovered rapidly, and after 30 minutes of rewarming, when the temperature had reached normothermia, essentially all observed areas had returned to baseline FCD.

The survival rate in the current study was $88 \%$, and both premature deaths occurred after 2 hours of DHCA. This no doubt reflects the severity of our DHCA protocol. In terms of behavioral assessment, however, a better outcome was seen among aprotinin-treated animals. Histologic scores were quite low, except when DHCA was used. After DHCA, aprotinin was associated with reduced histologic damage, but because of the limited number of animals, a statistically significant difference was not found. After low-flow CPB, no significant differences in histologic scores were found between aprotinin-treated and control animals, although at $34^{\circ} \mathrm{C}$, scores tended to be lower with aprotinin.

Our data suggest that aprotinin mitigates the inflammatory response and improves neurologic outcome after a prolonged period of DHCA and low-flow CPB. The distribution of serine proteases throughout the vasculature and their central role in the inflammatory response might explain how a serine protease inhibitor, such as aprotinin, can result in such a profound anti-inflammatory mechanism of action.

In light of our results and other published studies, it seems evident that aprotinin can reduce the inflammatory response. However, an interesting question to be explored is whether aprotinin penetrates the blood-brain barrier and might protect neuronal cells directly during ischemic damage in vivo. Additional studies are needed to provide clarification on this fundamental issue.

\section{References}

1. van Oeveren W, Jansen NJ, Bidstrup BP, et al. Effects of aprotinin on hemostatic mechanisms during cardiopulmonary bypass. Ann Thorac Surg. 1987;44:640-5.

2. Royston D, Bidstrup BP, Taylor KM, Sapsford RN. Effect of aprotinin on need for blood transfusion after repeat open-heart surgery. Lancet. 1987;2:1289-91.

3. Landis RC, Asimakopoulos G, Poullis M, Haskard DO, Taylor KM. The antithrombotic and antiinflammatory mechanisms of action of aprotinin. Ann Thorac Surg. 2001;72:2169-75.
4. Kamiya T, Katayama Y, Kashiwagi F, Terashi A. The role of bradykinin in mediating ischemic brain edema in rats. Stroke. 1993;24:571-5.

5. Hill GE, Alonso A, Spurzem JR, Stammers AH, Robbins RA. Aprotinin and methylprednisolone equally blunt cardiopulmonary bypass-induced inflammation in humans. J Thorac Cardiovasc Surg. 1995;110:1658-62.

6. Asimakopoulos G, Kohn A, Stefanou DC, Haskard DO, Landis RC, Taylor KM. Leukocyte integrin expression in patients undergoing cardiopulmonary bypass. Ann Thorac Surg. 2000;69:1192-7.

7. Asimakopoulos G, Thompson R, Nourshargh S, et al. An anti-inflammatory property of aprotinin detected at the level of leukocyte extravasation. J Thorac Cardiovasc Surg. 2000;120:361-9.

8. Cepinskas G, Noseworthy R, Kvietys PR. Transendothelial neutrophil migration. Role of neutrophil-derived proteases and relationship to transendothelial protein movement. Circ Res. 1997;81:618-26.

9. Carmeliet P, Moons L, Lijnen R, et al. Urokinase-generated plasmin activates matrix metalloproteinases during aneurysm formation. Nat Genet. 1997;17:439-44.

10. Moons L, Shi C, Ploplis V, et al. Reduced transplant arteriosclerosis in plasminogen-deficient mice. J Clin Invest. 1998;102:1788-97.

11. Murtomaki S, Trenkner E, Wright JM, Saksela O, Liesi P. Increased proteolytic activity of the granule neurons may contribute to neuronal death in the weaver mouse cerebellum. Dev Biol. 1995;168:635-48.

12. Lancelin JM, Foray MF, Poncin M, Hollecker M, Marion D. Proteinase inhibitor homologues as potassium channel blockers. Nat Struct Biol. 1994;1:246-50.

13. Siao CJ, Tsirka SE. Extracellular proteases and neuronal cell death. Cell Mol Biol. 2002;48:151-61.

14. Forbess JM, Ibla JC, Lidov HG, et al. University of Wisconsin cerebroplegia in a piglet survival model of circulatory arrest. Ann Thorac Surg. 1995;60(suppl):S494-500.

15. Miura T, Laussen P, Lidov HG, DuPlessis A, Shin'oka T, Jonas RA. Intermittent whole-body perfusion with "somatoplegia" versus blood perfusate to extend duration of circulatory arrest. Circulation. 1996; 94(suppl):II56-62.

16. Shin'oka T, Shum-Tim D, Jonas RA, et al. Higher hematocrit improves cerebral outcome after deep hypothermic circulatory arrest. J Thorac Cardiovasc Surg. 1996;112:1610-20.

17. Wallenstein S, Zucker CL, Fleiss JL. Some statistical methods useful in circulation research. Circ Res. 1980;47:1-9.

18. Boyle EM Jr, Pohlman TH, Johnson MC, Verrier ED. Endothelial cell injury in cardiovascular surgery: the systemic inflammatory response. Ann Thorac Surg. 1997;63:277-84.

19. Carlos TM, Harlan JM. Leukocyte-endothelial adhesion molecules. Blood. 1994;84:2068-101.

20. Anttila V, Hagino I, Zurakowski D, Lidov HG, Jonas RA. Higher bypass temperature correlates with increased white cell activation in the cerebral microcirculation. J Thorac Cardiovasc Surg. 2004;127:1781-8.

21. Poullis M, Manning R, Laffan M, Haskard DO, Taylor KM, Landis RC. The antithrombotic effect of aprotinin: actions mediated via the protease-activated receptor 1. J Thorac Cardiovasc Surg. 2000;120: $370-8$. 